\title{
STUDENT ENGAGEMENT: MORE THAN BELLS AND WHISTLES
}

\author{
Elizabeth Snyman-Van Deventer \\ Bluris LLB LLM LLM LLD \\ Department of Mercantile Law \\ University of the Free State
}

\begin{abstract}
SUMMARY
Student engagement is the time, effort and energy that students spend on all educational activities that enhance their learning ability. The improvement of student engagement is the principal aim of the Learning in Law project embarked upon by the Department of Mercantile Law at the University of the Free State (UFS), South Africa. One of the aims of the project, which is run in collaboration with the university's Centre for Teaching and Learning, is to help lecturers develop innovative teaching methods and techniques to ensure in-class student engagement. As modern-day students are used to fast access to information, entertainment and social activity via their mobile devices, new teaching methods to catch and hold their attention and promote participation are needed. This contribution not only makes the case for new ways of teaching law in a changing higher education environment, but also suggests specific steps and techniques to be considered, drawing from the experience of the UFS's Department of Mercantile Law.
\end{abstract}

1

\section{INTRODUCTION}

A faculty of law (or law school) has a duty not only to teach basic legal principles, ${ }^{1}$ but also to equip law students with higher-order thinking abilities, academic competencies and practical legal skills. This is confirmed by Elton, ${ }^{2}$ who states that three interests of students need to be served namely, their self-interest in passing examinations, their interest in the subject, and their interest in developing abilities that will be of value even after formal education. In serving these interests, the lecturer needs to help students develop the ability to analyse ${ }^{3}$ synthesise, make judgements and see a task through to its conclusion. ${ }^{4}$ Botein agrees that law students must

See Kirchner "Legal Ethics Education in Germany" 20152 The Indonesian Journal of International and Comparative Law 98107.

2 Elton "Research and Teaching: Conditions for a Positive Link [1]" 20016 Teaching in Higher Education 4347.

3 See Richie "Using John Dewey's Pragmatism Epistemology to teach Legal Analysis and Communication" 20125 Crit 1-27.

4 Elton 2001 Teaching in Higher Education 47. 
be taught "the vital lawyering skills of researching, synthesizing, and writing".

Ongoing higher education restructuring and reform in South Africa amid instability and student unrest poses unique circumstances that differ from experiences elsewhere. ${ }^{6}$ This influences the way students learn and engage in their learning and their participation in teaching. Strydom and Mentz identified several challenges facing South African higher education: (i) very low pass rates, (ii) low participation rates of previously excluded Black African students, (iii) students not adequately prepared in high school, (iv) one in three Black African students graduate in time, (v) widening access and an increased demand for graduates in the knowledge economy lead to unprecedented levels of diversity and many first-generation students, and (vi) socio-economic, capacity and resources constraints. ${ }^{7}$

Although many of the issues faced by law faculties and lecturers in the changing post-1994 tertiary education landscape are shared by all other disciplines, the teaching of law - particularly in the South African context does pose certain unique challenges. Increasingly, law lecturers find themselves having to devise new teaching methods and styles to ensure optimal student learning. Indeed, times have changed since law lecturers simply delivered a monologue and, at most, used argumentative debate (or the Socratic method) to drive home legal principles to their students. Gone are the days when the purpose of the law lecturer was to teach law students to think like lawyers, without also equipping them with practical legal skills. ${ }^{8}$ Shifts in the student body and in the social, political and economic environment in which a law faculty operates have seen this situation change dramatically. The modern student has access to various forms of electronic media and communication platforms, and is active on, and well-versed in, social media. The twenty-first-century student has access to information, anywhere and anytime, which also drives the desire for instant knowledge, entertainment and information. The introduction of different or "new" teaching methods is thus a necessity to ensure student learning - not mere bells and whistles or a gimmick.

This article sets out to illustrate the need for new ways of teaching law in the twenty-first century and beyond, and how law lecturers can go about promoting greater student engagement by catering to students' changing needs. Following a brief description of the rapidly transforming higher education scene, the focus of the article shifts to student engagement, the role of the law lecturer in facilitating such engagement, and the specific initial steps taken by the University of the Free State (UFS) Department of

5 Botein "Rewriting First-year Legal Writing Programs" 198030 Journal of Legal Education 184184.

6 Wawrzynski, Heck and Remley "Student Engagement in South African Higher Education" 201253 Journal of College Student Development 106106

7 Strydom and Mentz Focusing the Student Experience on Success through Student Engagement (2010) 4.

8 Wood and Reeson "Experiential Learning in Restructuring Law" 201556 The Canadian Business LJ 325326 
Mercantile Law in this regard. It is hoped that this article will stimulate debate and creative thinking in respect of teaching law in an innovative way.

\section{SOUTH AFRICAN TERTIARY EDUCATION: THE ONLY CONSTANT IS CHANGE}

\section{Technology}

No different from their fellow citizens of the globalised world, through the introduction of technology, South Africans too have experienced rapid changes in the way they do business, communicate and live. Over the past few decades, technological aids have found their way into every sphere of life (including tertiary education) and have transformed the way we teach and learn. In this regard, Fourie and Coetzee emphasise that the rapidly changing social, economic and intellectual environment requires a shift in teaching and learning from the mere transmission of knowledge ("learning about") to the creation of a knowledge domain ("learning to be").

Students ${ }^{10}$ are heavily dependent on mobile devices such as cellphones, smartphones, tablets and laptops for social networking, sourcing information in seconds, and communicating in various ways, 24/7. This lifestyle of instant information, responses and gratification places new demands on the law lecturer as the facilitator of learning; the challenge is to ensure that students are engaged in lectures, their studies and the actual learning of law. Since platforms such as Facebook, Instagram, Twitter, blogs and other social media are already frequented by students, there is ample opportunity to use these as effective learning engagement tools to capture and retain students' attention.

\section{A changing student body}

The post-1994 government set out to ensure access to tertiary education (including broader access to legal education) for previously disadvantaged students. This has introduced dramatic shifts in the composition of the student body at most of the country's universities. The UFS, for one, has changed from a predominantly white, Afrikaans-speaking institution to a parallel-medium English and Afrikaans university, with more than 68 per cent of its enrolled students being black Africans. Student numbers have also increased markedly: at the UFS, for example, more than 600 students have enrolled for the first-year course in Family Law. In 2015, the Law of Business Entities module (which forms part of third-year law studies and is taught by

$9 \quad$ Fourie and Coetzee "The Use of a Therapeutic Jurisprudence Approach to the Teaching and Learning of Law to a New Generation of Law Students in South Africa" 201215 Potchefstroom Electronic LJ 367367.

10 For a discussion of the twenty-first-century law student, see Matthew "Managing Distraction and Attention in Diverse Cohorts: $21^{\text {st }}$ Century Challenges to Law Student Engagement" 201212 Queensland University of Technology Law and Justice Journal 45 48-50; Palmer "The Millennials are Coming!: Improving Self-efficacy in Law Students through Universal Design in Learning" 201563 Cleveland State LR 675-706. 
the author) had 160 English and 105 Afrikaans enrolled students - up from an average of 120 Afrikaans and 50 English students in earlier years. In 2016, the same module had 203 English and 53 Afrikaans students. In 2017, there were 70 Afrikaans and 282 English students in this module.

Inevitably, this has had implications for the way we teach: there is now a need for lecturers to teach in both Afrikaans and English (either different lecturers each teaching in one language or one lecturer proficient in both) ${ }^{11}$ and, lecturers need to take into account students' varying cultural and scholastic backgrounds, and at the same time recognise individual students' abilities, expectations and way of learning.

Adding to these complexities, the UFS Faculty of Law also has online students who do not attend lectures on campus, but use the Blackboard platform for their studies. When preparing lectures and learning material, lecturers now also have to keep in mind that some 50 students do not physically attend class, but listen to audio recordings of lectures and rely on the material, communications and announcements placed on Blackboard.

\section{Students' academic and other skills}

In teaching substantive law principles and skills, the lecturer must also be mindful of the multiple barriers to learning that students face. These include a lack of confidence, inexperience in tertiary education, inability to understand and communicate new concepts, lack of knowledge of how to study a specific new body of knowledge, and disillusionment about their own abilities and skills. ${ }^{12}$

South African students enrol for the LLB degree programme fresh from the school bench. This has an impact on their academic and intellectual standard and abilities. In addition, many law students belong to the so-called "new generation", a number of whom may be the first in their families to enter university studies, ${ }^{13}$ meaning that they are often ill-prepared for the demands of higher education and lack basic academic reading and writing skills. ${ }^{14}$ This in turn requires law teachers to incorporate the teaching of basic legal reading and writing skills into their respective subjects. Unfortunately, similar to the situation in the United States (USA), the theory and practice of law have been separated in South African legal education, ${ }^{15}$

This will of course change as Afrikaans is phased out at the UFS.

12 Enns "Students Critiquing Novice Writing: Building Hope by Building Bridges" 201048 Duquesne LR 403-411; Biggs and Hurter "Rethinking Legal Skills Education in an LLB Curriculum" 201439 Journal for Juridical Science 12.

13 Fourie and Coetzee 2012 Potchefstroom Electronic LJ 367.

14 Boughey "South Africa: University Students Can't Read?" (2009) http://www.university worldnews.com/article.php?story=20090827173247724\&query=Boughey (accessed 201306-19); Boughey "Social Inclusion \& Exclusion in a Changing Higher Education Environment" 20122 Multidisciplinary Journal for Education Research 133-138; Biggs and Hurter 2014 Journal for Juridical Science 2.

15 Robbins-Tiscione "A Call to Combine Rhetorical Theory and Practice in the Legal Writing Class Room" 201150 Washburn LJ 319 319; Posner "Legal Scholarship Today" 2002115 Harvard LR 1314 1314-1317; Edwards "The Growing Disjunction between Legal Education and the Legal Profession" 199291 Michigan LR 34 34-35. 
and lecturers in doctrinal or black-letter law subjects often find it difficult, or regard it as unnecessary and time-consuming, to incorporate legal writing exercises into their teaching.

\section{Changes to the LLB programme}

Another major change to legal education in South Africa was introduced in 1998 when universities had to make the transition from offering an undergraduate law degree followed by an LLB (in other words, an initial three- or four-year undergraduate programme, followed by a two-year LLB programme) to offering a four-year LLB degree. ${ }^{16}$ This forced law faculties to reconsider the subjects or modules required to deliver graduates who will be able to function in the legal profession, bearing in mind that an LLB is a requirement for admission to practise law as either an attorney or advocate. Having a year less within which to complete the LLB, the number of subjects had to be reduced.

Furthermore, the development of both knowledge and skills is recognised as extremely important in producing employable graduates who have the ability to become successful legal practitioners. ${ }^{17}$ For this reason, law faculties have a duty towards the legal profession to integrate theory, legal skills, doctrines and principles into the teaching of law. ${ }^{18}$ Students should therefore not only learn black-letter law, but also the skills to analyse a legal problem, identify the issue at stake, determine the applicable principle(s) and apply the law to the problem or situation. This is unfortunately not achieved by standing in front of a class and delivering an hour-long talk, while students frantically take notes.

Most law faculties in South Africa have initiated curriculum reform processes owing to: i) the South African legal fraternity's constant criticism of law students' abilities (or lack thereof); ii) law faculties' own recognition that the current LLB needs to be revised; ${ }^{19}$ iii) the outcomes of the National Review of the Bachelor of Laws (LLB) Programme (with specific focus on the requirements for re-accreditation); and iv) the Qualification Standard for Bachelor of Laws (LLB) of the Council for Higher Education. This move

16 In terms of the Qualification of Legal Practitioners Amendment Act 78 of 1997. Also see the discussion by Greenbaum "The Four-year Undergraduate LLB: Progress and Pitfalls" 2010 35 Journal for Juridical Science 2 2-3; Van Niekerk "The Four-year Undergraduate LLB: Where to from here?" 201334 Obiter 533 533-534; Snyman-Van Deventer and Swanepoel "Teaching South African Law Students (Legal) Writing Skills" 20133 Stellenbosch LR 510 512.

17 Du Preez and Fossey "Developing Academic Writing Skills as Part of Graduate Attributes in Undergraduate Curricula" 201226 South African Journal for Higher Education 346 346-347; Feeley "Training Field Supervisors to be Efficient and Effective Critics of Student Writing” 200915 Clinical LR 211212.

18 Schmedemann "Do Best Practices in Legal Education Include an Obligation to the Legal Profession to Integrate Theory, Skills, and Doctrine in the Law School Curriculum?" 20021 Journal of the Association of Legal Writing Directors 127127.

19 Greenbaum "Current Issues in Legal Education: A Comparative View" 201223 Stellenbosch LR 16 16-32; Van Niekerk 2013 Obiter 534-536; Biggs and Hurter 2014 Journal for Juridical Science 2-3. 
towards recurriculating the LLB answers calls by, inter alia, Greenbaum, ${ }^{20}$ who has stated that South African legal educators should increasingly engage in scholarly discourse on legal education. It is also aimed at aligning the LLB in particular, as well as the teaching of law in general, with the Higher Education Qualifications Framework (HEQF), which states: ${ }^{21}$

\footnotetext{
"[A bachelor's degree] has the primary purpose of providing a well-rounded, broad education that equips graduates with the knowledge base, theory and methodology of disciplines, and enables them to demonstrate initiative and responsibility in an academic or professional context."
}

Thus, the need for change in the way we teach at university (and teach law, specifically) is clear. To best serve twenty-first-century law students as well as the law profession, we need to acknowledge the needs of the student body, the expectations of government and the legal profession, the time and credits available for the modules we teach, and the imperative to equip students with practical legal skills.

\section{TEACHING AND LEARNING: LEARNING CONCEPTS AND STATEGIES}

Every student has his or her own mental model of learning. It is a combination of the student's conception of learning and includes the learning itself, what they are learning and thinking, their role in the learning process, their lecturers' role in the learning process, the role of their classmates in the learning process, and the demands of the learning tasks. ${ }^{22}$ Spreng explains that these mental models influence a student's learning strategies and behaviours. ${ }^{23}$

In determining teaching and lecturing methods, the lecturer must take into account the learning behaviour of students, which can be either active or passive. ${ }^{24}$ Active learning refers to anything that a student does beyond just listening and watching. Passive learning is the traditional listening, watching and taking notes. ${ }^{25}$ Even during a discussion in class, some students are still only engaged in passive learning, because they do not participate and may not understand the dialogue taking place ${ }^{26}$ Active learning occurs not only in the classroom, but may start already with students actively preparing for class. Engaged reading contributes further to active learning where students have to apply higher-thinking skills such as, for example, connecting ideas and sources of information.

\footnotetext{
Greenbaum 2012 Stellenbosch LR 16-39.

GN 928 in GG 30353 of 2007-10-05.

Spreng "Spirals and Schemas: How Integrated Courses in Law Schools Create Higherorder Thinkers and Problem Solvers" 201537 University of LA Verne LR 3743.

Ibid.

Spreng 2015 University of LA Verne LR 45

Ibid.

Spreng 2015 University of LA Verne LR 46.

Ibid.
} 
Closely linked to active and passive learning, is a student's deep or surface learning strategy. ${ }^{28}$ Surface learning is the acquisition of superficial knowledge. $^{29}$ The student will most probably not remember much of the study material after an assessment. Students use surface learning to remember only what is necessary for an assessment and will often just memorise facts. ${ }^{30}$ Active learners will use deep learning strategies and their concept of learning is about something that they do. ${ }^{31}$ They will read more widely and will use evidence, determine the logic of an argument, will try to make connections between prior knowledge and new knowledge and between knowledge and experience. ${ }^{32}$

While teaching, law lecturers have to recognise that their classroom performance and presentation should promote active, deep learning. The law lecturer should demand active learning in the classroom and active learning demands active engagement and participation by the students.

\section{DEFINING STUDENT ENGAGEMENT}

In layman's terms, student engagement can be described as the amount of time, effort and energy that students dedicate to educational activities so as to enhance their ability to learn. To O'Day and Kuh, student engagement encapsulates the notion that "the more students do something, the more proficient they become". ${ }^{33}$ Engagement includes preparation for class, participating in class and related activities such as moot courts, as well as interaction with fellow students and faculty members. Gordon and colleagues view active and interactive student engagement in the learning process as the polar opposite to the more traditional "memorization of facts and reciting them at exam time". 34 Hess too states that "[s]tudents become engaged in learning when they actively participate in their own education," while Palmer calls student engagement "self-regulated learning", whereby the student actively controls his or her own behaviour, motivation and thinking processes.

Zepke and Leach accept that student engagement is the students' cognitive investment and active participation in and emotional commitment

\footnotetext{
Spreng 2015 University of LA Verne LR 47.

Ibid.

Ibid.

Ibid.

Ibid.

O'Day and Kuh "Assessing What Matters in Law School: The Law School Survey of Student Engagement" 200681 Indiana LJ 401 401-406; also cited in Silver, Garver and Watkins "Unpacking the Apprenticeship of Professional Identity and Purpose: Insights from the Law School Survey of Student Engagement" 201117 Legal Writing Journal of the Legal Writing Institute 373379.

34 Gordon, Barnes and Martin "Undergraduate Research Methods: Does Size Matter? A Look at the Attitudes and Outcomes of Students in a Hybrid Class Format versus a Traditional Class Format" 200920 Journal of Criminal Justice Education 227229.

35 Hess "Heads and Hearts: The Teaching and Learning Environment in Law School" 200252 Journal of Legal Education 75101.

36 Palmer 2015 Cleveland State LR 678.
} 
to their learning, and it is also students' involvement with activities and conditions that may generate higher learning. ${ }^{37}$

Barkley approaches student engagement from two different perspectives. The first is that student engagement is rooted in motivation. From this perspective, engaged students are those who want to learn and who will exceed expectations and go beyond what is required of them. ${ }^{38}$ The other perspective views student engagement as relating to active learning, including higher-order thinking skills such as analysis, problem-solving, making sense of new information and connecting it to existing knowledge to deal with numerous scenarios as required. ${ }^{39}$ These two perspectives, Barkley argues, are not mutually exclusive. Student engagement should therefore not be a case of "either, or", but rather a combination of the two, getting the student motivated for and committed to his or her learning, as well as keeping the student actively involved.

Gordon suggests the following list of elements as contributors to active student engagement: (i) class attendance and active participation in class; (ii) hours of personal study, either alone or in a group; (iii) engagement with the discipline and/or attachment to the disciplinary community; (iv) collaborative and informal interaction with fellow students; (v) interaction with academic staff; and vi) engagement with a range of learning resources. ${ }^{40}$ Students must be at the centre of, and be actively involved in, the learning process and must observe and perceive, ask questions and discuss issues to construct their own understanding of the subject matter. ${ }^{41}$ They must also be supported and accommodated to feel safe and confident in the teaching and learning environment, including the classroom. In this regard, communication is of course vital. Where such a supportive, accommodating and encouraging environment is created, numerous primary goals of legal education are achieved, such as higher-level thinking skills, content mastery, professional skills and a positive attitude. ${ }^{42}$

Zepke and Leach identified ten key actions needed for student success: (i) enhance students' self-belief ${ }^{43}$ (ii) enable students to work autonomously, enjoy learning relationships with others and feel they are competent to achieve their own objectives; ${ }^{44}$ (iii) recognise that teaching and teachers are central to engagement; ${ }^{45}$ (iv) create learning that is active and collaborative and that fosters learning relationships; ${ }^{46}$ (v) create educational experiences for students that are challenging, enriching and extend their academic abilities; ${ }^{47}$ (vi) ensure institutional cultures are welcoming to students from

37 Zepke and Leach "Improving Student Engagement: Ten Proposals for Action" 201011 Active Learning in Higher Education 167168.

38 Barkley Student Engagement Techniques (2010) 5.

39 Barkley Student Engagement Techniques 5-6.

40 Gordon et al 2009 Journal of Criminal Justice Education 229.

41 Ibid.

42 Hess 2002 Journal of Legal Education 102.

43 Zepke and Leach 2010 Active Learning in Higher Education 169-170.

44 Zepke and Leach 2010 Active Learning in Higher Education 170.

45 Zepke and Leach 2010 Active Learning in Higher Education 170-171.

46 Zepke and Leach 2010 Active Learning in Higher Education 171

47 Ibid. 
diverse backgrounds; ${ }^{48}$ (vii) invest in a variety of support services; ${ }^{49}$ (viii) adapt to changing student expectations; ${ }^{50}$ (ix) enable students to become active citizens; ${ }^{51}$ and $(\mathrm{x})$ enable students to develop their social and cultural capital. $^{52}$

Two key components that influence student engagement are, firstly, what students do, and secondly, what institutions do. ${ }^{53}$ Strydom and Mentz list six institutional characteristics and conditions essential for student engagement and success namely: (i) a living mission and lived educational philosophy; ${ }^{54}$ (ii) an unshakeable focus on student learning; ${ }^{55}$ (iii) learning environments that promote educational enrichment; ${ }^{56}$ (iv) clear pathways to maximise student success; ${ }^{57}$ (v) an improvement-orientated institutional culture and ethos; ${ }^{58}$ and (vi) ownership by all in the institution of the quality of learning and student success.

Students must be actively engaged in their learning in order to learn and grow. Student engagement affects learning outcome and academic success. With the student at the centre of learning, what role is then left for the lecturer? It is proposed that the twenty-first-century lecturer should be the facilitator of active yet effective learning. This may be achieved by incorporating new techniques and ideas into teaching, taking into account different learning styles and study methods. ${ }^{60}$ Hess agrees: student engagement and motivation are enhanced where a variety of teaching and learning methods is used. ${ }^{61}$ Lecturers would therefore be well advised to try using different teaching methods and styles to ensure the engagement of all students in class. These include the use of electronic resources such as PowerPoint, the presentation software Prezi, video clips and podcasts, which may be presented in both face-to-face lectures or on digital learning platforms. Such teaching methods may then serve to supplement the comprehensive study guides, textbooks and relevant, useful prescribed material (such as case law and journal articles) to which students normally already have access.

Once lecturers have supplemented their usual teaching methods with these other ways of teaching, the key to translating them into successful student engagement seems to be to know where the lecturer's responsibilities as facilitator of active learning stop so that students can

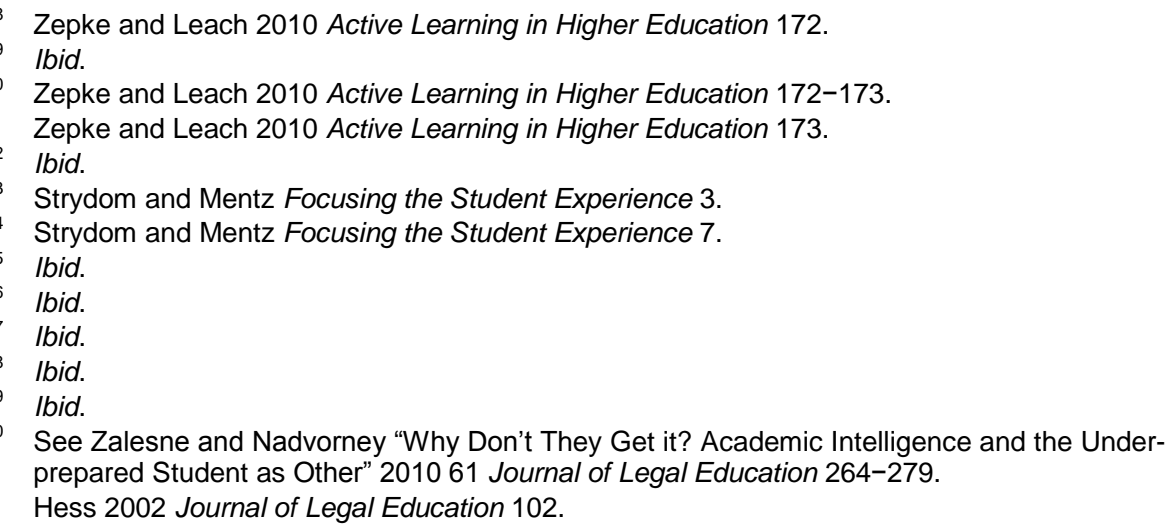


assume a central role in actively learning by themselves. A lecturer's task is to ensure that students are actively learning and thinking by equipping them with the tools they need to be able to learn what they are supposed to learn - not only the factual knowledge, but also the skills they will require to be successful in any practice of law.

Strydom and Mentz state:

"If South African higher education is going to improve the positive outcomes (such as $21^{\text {st }}$ century graduate attributes, as well as improved throughput and success) and design of the student experience, it is going to have to become more intentional and even include requiring students to participate in activities that will contribute to their improved chances of success."

\section{APPLYING THE THEORY: THE UFS “LEARNING IN LAW" PROJECT}

\section{How Learning in Law came about}

Against the backdrop of the "under-development" of legal education scholarship in South Africa, Greenbaum states that "limited attention is paid to pedagogical issues and educational research by legal academics who regard themselves, it would appear, in general, primarily as lawyers and not teachers ....". ${ }^{63}$ Lawyers acting as teachers is a phenomenon that presents barriers to learning to students, and has given rise to an urgent need for new ways of teaching and learning law at tertiary institutions, including at the UFS.

To enhance and improve student engagement, the Department of Mercantile Law has embarked on a collaborative project called Learning in Law with the university's Centre for Teaching and Learning. One of the aims of Learning in Law is to help lecturers develop innovative teaching methods and techniques to ensure improved student engagement in the classroom. The focus is to ensure that students participate and that they take responsibility for their own learning through preparation. Learning in Law has seen a range of novel teaching methods being introduced, and has changed teaching in the Department of Mercantile Law in its pursuit of improved student success and retention rates.

The project commenced with a needs analysis and round-table discussion. Participants explored topics such as the principles underlying tertiary teaching and learning, with specific attention being paid to teaching methods that could contribute to student engagement and learning. In particular, the Learning in Law project group focused on the seven principles of quality undergraduate education developed by the American Association of Higher Education's Gamson and Chickering, who established that good practice in legal education: (i) encourages student-faculty contact; (ii) encourages cooperation among students; (iii) encourages active learning;

\footnotetext{
Strydom and Mentz Focusing the Student Experience ix. Greenbaum 2012 Stellenbosch LR 16-32.
} 
(iv) gives prompt feedback; (v) emphasises time on task; (vi) communicates high expectations; and (vii) respects diverse talents and ways of learning. ${ }^{64}$

The project group then shifted its attention to Barkley's student engagement techniques (SETs). ${ }^{65}$ Each group member was assigned a SET to study, summarise and identify for possible use in teaching law (see next paragraph for more). After a discussion of the potential teaching techniques based on the SETs, the lecturers of the Department of Mercantile Law applied the techniques in their own classes to varying degrees.

\section{Barkley's student engagement techniques (SETs)}

Barkley identifies 50 SETs divided into two categories ${ }^{66}$ - namely, techniques to engage students in learning course-related knowledge, ${ }^{67}$ and skills and techniques for developing learner attitudes, values and selfawareness. ${ }^{68}$ The SETs are subdivided with reference to the specific learning objectives.

For category one, techniques to engage students in learning courserelated knowledge, five areas of learning are identified: (i) knowledge, skills, recall and understanding; (ii) analysis and critical thinking; (iii) synthesis and creative thinking; (iv) problem solving; and (v) application and performance. $^{69}$

In category two, skills and techniques for developing learner attitudes, values and self-awareness, the identified areas of learning are: (i) attitudes and values; (ii) self-awareness as learners; and (iii) learning and studying skills. ${ }^{70}$

The Learning in Law project group concentrated on those SETs that might be of use for teaching law, focusing primarily on category-one techniques to engage students in learning course-related knowledge. A number of Mercantile Law lecturers subsequently implemented some of the SETs in their classes, as the following paragraphs will illustrate. Note, however, that owing especially to time constraints, this was done once or twice and for specific purposes, while the rest of the work was dealt with in normal lecture style. In addition, the SETs should be used in accordance with the lecturer's style and personality, and should also suit the objective or learning outcomes of the specific lecture.

64 Hess "Seven Principles for Good Practice in Legal Education" 199949 Journal of Legal Education 367 367-370.

65 Barkley Student Engagement Techniques 149-361.

66 Ibid.

67 Barkley Student Engagement Techniques 149-299.

68 Barkley Student Engagement Techniques 300-361.

69 Barkley Student Engagement Techniques 149-299.

70 Barkley Student Engagement Techniques 300-361. 


\section{Initial steps taken by Learning in Law}

The following table summarises the student engagement techniques applied by members of the Learning in Law project groups at UFS's Department of Mercantile Law. Each technique along with its practical application is elaborated on in the paragraphs below the table. Some (though not all) of the new techniques are based on the SETs discussed in the Learning in Law group, and most lecturers adapted the SETs to suit their teaching styles, personalities as well as other specific circumstances, such as classroom setup and number of students.

Table 1: Student engagement techniques (SETs) applied by Learning in Law

\begin{tabular}{|l|l|l|}
\hline $\begin{array}{l}\text { Student engagement } \\
\text { technique }\end{array}$ & $\begin{array}{l}\text { Practical application } \\
\text { at UFS }\end{array}$ & $\begin{array}{l}\text { Educational } \\
\text { goal/teaching objective }\end{array}$ \\
\hline Technology & $\begin{array}{l}\text { Music } \\
\text { YouTube and } \\
\text { newspaper reports } \\
\text { Video clips } \\
\text { Podcasts } \\
\text { Blackboard } \\
\text { Online website }\end{array}$ & $\begin{array}{l}\text { Knowledge, recall and } \\
\text { understanding; } \\
\text { application and } \\
\text { performance; analysis } \\
\text { and critical thinking }\end{array}$ \\
\hline Quotes & $\begin{array}{l}\text { Beach ball } \\
\text { Balloons with quotes } \\
\text { Quotes on paper }\end{array}$ & $\begin{array}{l}\text { Knowledge, recall and } \\
\text { understanding }\end{array}$ \\
\hline Jigsaw & $\begin{array}{l}\text { Sentences from } \\
\text { judgments linked }\end{array}$ & $\begin{array}{l}\text { Application and } \\
\text { performance }\end{array}$ \\
\hline Groups & $\begin{array}{l}\text { Problems or case } \\
\text { studies discussed }\end{array}$ & $\begin{array}{l}\text { Analysis and critical } \\
\text { thinking }\end{array}$ \\
\hline Game shows & $\begin{array}{l}\text { Playing "Who Wants to } \\
\text { Be a Millionaire" and } \\
\text { "30 Seconds" }\end{array}$ & $\begin{array}{l}\text { Knowledge, recall and } \\
\text { understanding }\end{array}$ \\
\hline Written assignments & $\begin{array}{l}\text { Writing summaries of } \\
\text { judgments and journal } \\
\text { articles }\end{array}$ & $\begin{array}{l}\text { Analysis and critical } \\
\text { thinking }\end{array}$ \\
\hline $\begin{array}{l}\text { Olassroom } \\
\text { assessment }\end{array}$ & $\begin{array}{l}\text { One-minute essay } \\
\text { Feedback }\end{array}$ \\
\hline
\end{tabular}




\section{Use of technology}

Pointing out the benefits of incorporating technology into teaching, Matthew states:

"The use of a variety of emerging technologies to foster student engagement and direct and deploy student attention is consistent with accepted theory of effective teaching and learning. It seeks to support a range of learners with different learning styles and, similarly scaffolds a range of different teaching methods and preferences. Best practice would typically also involve a strong presence of the teacher who uses the features of the technology to interactively gauge student understanding and dynamically scaffold the learning experience in response to the feedback."

At the same time, however, Matthew cautions that using technology without considering the required educational outcomes could prove pointless. $^{72}$ This warning should be heeded in introducing new student engagement techniques in the teaching of law.

\section{(i) Music}

At the July 2013 EDULEARN conference in Barcelona, ${ }^{73}$ one of the presenters explained how he had introduced music into his classes. This was put to the test in a third-year Law of Business Entities module at UFS. Music was played in class before the start of the lecture while the lecturer was finalising all administrative work. Along with the music, a self-playing PowerPoint slideshow that added to the lecture content was screened. For example, before a lecture on the history of the Law of Partnership, the slideshow centred on the Code of Hammurabi. Pictures in the PowerPoint or Prezi presentations of the lecture itself were used to ensure that maximum visual learning could take place.

\section{(ii) YouTube and newspaper reports}

Also in the Law of Business Entities module, for the learning unit on stokvels (the traditional South African rotating savings club that forms part of township life), newspaper reports and a YouTube video constituted the only prescribed material. Since the prescribed material was so entirely different from the usual law textbooks, journal articles and case law, most students did in fact read the newspaper reports and used the information in writing a required essay on the economic and social role of stokvels in South Africa. To be able to write the essay, students had to read the material and watch the YouTube clip, while they were also free to engage with other forms of learning material.

While it is important to expose students to everyday sources of information in the field of law, it is also vital that they understand that newspaper reports are not authoritative, but only informative, and are therefore not a primary source of law.

\footnotetext{
Matthew 2012 Queensland University of Technology Law and Justice Journal 53.

Ibid.

Edulearn 13, $4^{\text {th }}$ International Conference on Education and New Learning Technologies, 1-3 July 2013, Barcelona, Spain.
} 


\section{(iii) Video clips}

Another lecturer has started using video clips at the beginning of each lecture, linking all subsequent work to the clip. She also refers to the clip when putting questions to students, which forces them to apply the theory or black-letter law to the specific situation or incident depicted in the clip.

Note that this lecturer is fortunate enough to have fewer than 50 students in her module. This enables her to ensure that all students are engaged in interactions during lectures through the discussion of the video clips.

\section{(iv) Podcasts}

In the second-year module on Labour Law, the lecturer used podcasts to explain basic definitions and principles, which students had to watch before they attended class. In practice, few students actually watched the podcasts before class, but ended up doing so before assessments and as part of their preparation for tests and examinations.

\section{(v) Blackboard}

As all lecturers and students at UFS (both on-campus and online) have access to and utilise Blackboard (an online portal to all modules and courses), this is also used as a platform to engage students. Blackboard is used to communicate with students and also provides them with access to audio recordings of all lectures, as well as the PowerPoint or Prezi presentations used in class. Both campus and online students make use of these resources. In addition, Blackboard is also used to post notes and additional reading material, announcements, messages and general feedback on assessments.

\section{(vi) Online website to buy shares}

In 2017, a Company Law lecturer in the Law of Business Entities module used a website "Easyequities" to show students how to buy and sells shares listed on the Johannesburg Stock Exchange. Seeing these transactions contributed to a better understanding of what shares are, how they work and how value is attached to shares. The lecturer also showed students the websites of different companies they are familiar with and used the annual year report and notice of meetings on these websites to teach the theory of Company Law - for example, the content of the notice for an annual general meeting, the notice date and record date and how to determine these dates.

\section{Beach ball, balloons and other games}

\section{(i) Beach ball}

One Mercantile Law colleague had trouble getting students to participate in class discussions. At a Learning in Law meeting, it was suggested that she take a beach ball to class and throw it towards the students. The rules of the game were that the student who caught the ball had to answer the question, and could subsequently pass on the ball to whomever he or she wanted. At first, many students perceived it as a joke, but soon realised that this 
seemingly fun technique was accompanied by an expectation of productive participation and interaction in class.

The benefit of this method is its quick tempo, forcing students to respond immediately. It also contributed to a relaxed and open class atmosphere in which students felt safe to answer questions.

\section{(ii) Quotes on paper and in balloons ${ }^{74}$}

To ensure that students read and understood the prescribed case law, typed paragraphs from the different judgments were handed to them. The lecturer then read out the case name in class and the students had to connect their paragraphs with the right judgment. This quickly turned into a contest, and students soon insisted on "playing the game again". Upon playing it a second time, it was evident that everyone had read the cases before class.

Another method employing quotes to ensure students read the prescribed case law was to put the typed paragraphs from the judgments into balloons. The balloons were then tossed around by the students until they burst, leaving the student with the burst balloon to identify the relevant judgment. Again, this contributed to a more relaxed class atmosphere, although it was rather time-consuming having to wait for the balloons to burst.

\section{Jigsaw $^{75}$}

An adaptation of the jigsaw SET was successfully used to ensure that students not only read the prescribed case law, but also understood it. Single sentences from four different judgments were typed out on separate pieces of paper. The class was divided into four groups, and each received an equal number of the typed sentences. With the lecturer reading out the first sentence from one of the judgments, the students then had to identify the following sentences until the specific extract from the judgment was completed. Once the extract was completed, the groups also had to identify the specific judgment.

\section{Small groups}

In the third-year module on Consumer Protection, the lecturer divided the class into smaller groups to discuss specific problems or sets of facts. The groups then gave feedback in class through a self-appointed group leader. Typically, each group would receive a different problem or set of facts within the area of learning - for example, each group would get to deal with a different form of breach of contract.

\footnotetext{
See Barkley Student Engagement Techniques 167-169. Ibid.
} 


\section{Game shows $^{76}$}

In the fourth-year Insolvency Law module, the class played "Who Wants to $\mathrm{Be}$ a Millionaire". The lecturer handed out chocolates as prizes, and everybody in class participated. This method elicited extremely positive feedback afterwards by way of a questionnaire. In the subsequent test, students performed better than average in the questions from the "Millionaire" lecture. This method proved very successful in engaging the entire class in the lecture.

Another, similar method to teach students definitions and basic principles is "30 Seconds". This was employed in the second-year Interpretation of Laws module, with very favourable outcomes.

\section{Written assignments}

In Law of Business Entities, students were required to complete ten assignments of two pages each on different aspects of Company Law. In each assignment, they were asked to read prescribed material and then write a summary. This meant that students had, for example, to summarise an article of 20 pages or a judgment of 50 or more pages in the required two pages. The assignment served a dual purpose, requiring students to read the prescribed material, but at the same time teaching them the important skill of summarising different legal texts. However, this was very time consuming and the lecturer battled to give feedback on all the assignments. In future, the number of assignments will be limited to not more than five.

Another pedagogy that may be employed to develop students' ability to critically analyse is to take legislation or parts of it and ask students to "redraft" the law into a more comprehensible form, or to explain what it actually means. One Mercantile Law colleague used the definition of "gross income" in the Income Tax Act as a means not only to teach very important terminology, but also to teach the skills needed to read, interpret and summarise a definition spanning more than 30 pages. Through this exercise, students learnt how to rephrase the definition into a shorter, more comprehensible form, while at the same time grasping some important doctrinal theory on the subject. In the process, legal skills and theory were integrated.

\section{Classroom assessment ${ }^{77}$}

Finally, one-minute essays ${ }^{78}$ were used to ascertain students' understanding of the work dealt with in the previous lecture, determine what they perceived to be the salient aspects of the lecture, as well as for the lecturer to establish how effective his teaching had been. The lecturer found it useful, but

76 Barkley Student Engagement Techniques 289-295.

77 Hess "Student Involvement in Improving Law Teaching and Learning" 199867 UMKC LR 342346.

78 Hess 1998 UMKC LR 344-345. 
concluded that students should rather write the essays at the end of each lecture, and not during the following lecture.

\section{CONCLUSION}

By taking these initial steps in introducing new methods to teach law, the Department of Mercantile Law at UFS is aiming to place students at the centre of the learning process, where they can be actively involved in their own learning and have ample opportunity to perceive, observe, ask questions and discuss issues so as to construct their own understanding. However, the crux of the matter is that it is still necessary for students to put in the effort and actually study.

Lecturers are neither performers, nor entertainers, but are facilitators of learning. Therefore, any change to teaching methods and styles must be more than a novelty, a gimmick, or mere bells and whistles; they must truly help cultivate a culture of learning. Yet, we cannot deny that the students of 2018 and beyond are no longer the students of the 1980s or even the 1990s. They are accustomed to a vastly different environment in which information is available at every turn and at all times. The art will therefore be to strike the right balance between catering to twenty-first-century students' needs to enhance their engagement on the one hand, and still encouraging a culture of learning on the other.

Although at UFS, the Learning in Law project and the Department of Mercantile Law are not yet moving mountains, the examples cited above show the lecturers' commitment and dedication to improving their teaching by bringing innovative and original teaching methods to their classes. By doing the same things differently as well as doing completely new things, lecturers succeeded in whetting students' appetite for the subject matter and encouraged improved preparation for and participation in class. All participating lecturers reported improvements in students' semester marks compared to previous years, which is the ultimate goal. 